\title{
DIELECTRICAL ANALYSIS OF COMPOSITE MATERIALS WITH RECYCLED CARBON FIBERS
}

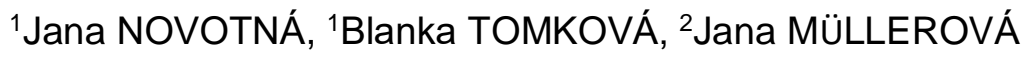 \\ ${ }^{1}$ Department of Material Engineering, Technical University of Liberec, Faculty of Textile engineering, Liberec, \\ Czech Republic,EU, jana.novotna3@tul.cz, blanka.tomkova@tul.cz \\ ${ }^{2}$ Technical University of Liberec, Institute for Nanomaterials, Advanced Technology and Innovation, Liberec, \\ Czech Republic, EU, jana.mullerova@tul.cz
}

https://doi.org/10.37904/nanocon.2020.3690

\begin{abstract}
A series of thin epoxy resin samples were prepared. Short recycled carbon microfibers in concentrations from $0 w t \%$ to $33 w t \%$ were used as composite fillers. The geometry and structure of these fillers were characterized using SEM and Raman DXR microscopy images. It has been found that the dielectric properties of composites strongly depend on the RCF content and show an increase in values at and above the percolation threshold. Below the percolation threshold, the distance between the fibers is large enough so that there is no interaction of the local fields created by the adjacent fibers and the dielectric constant in this region increases slowly. As the filler concentration increases, the Maxwell Wagner effect increases and leads to a sharp increase in the real permittivity values. Furthermore, it was found in this work that the permittivity increases with increasing concentration of particles even after reaching the percolation threshold over the entire frequency band.
\end{abstract}

Keywords: Recycled carbon fibers (RCFs), epoxy composites, dielectrical properties

\section{INTRODUCTION}

By studying new materials concerning their use in electrical engineering, one of the most important properties is the dielectric constant of the material and its frequency dependence. This work describes the changes in dielectric properties of carbon fiber reinforced composites CFCRs as a function of filler content. The obtained data are analyzed from percolation theory [1], which was experimentally determined at a concentration of 20 wt \% [2]. The dielectric behaviour of filled conductive composites is in the case of heterogeneous systems subject to interface polarization, where one of the components of the composite has a higher electrical resistance compared to the others [3] [4]. This is generally known as the Maxwell Wagner effect [5].

\subsection{Carbon fiber (CFs)}

CFs rovings are mainly used to reinforce polymers, similar to fibreglass (glass rovings embedded in various resins), and form high-performance composite materials. CFs have higher strength and lower density compared to glass fibers [6]. So far, however, insufficient attention has been paid to the use of recycled carbon fibers (RCF), which is an essential fibrous raw material, the amount of which will increase with the increasing use of $\mathrm{CF}$ in the composite industry [7]. To expand CF recycling it is necessarey to specify how recycled carbon fibers will be used. Carbon fibers are primarily used for the reinforcement of composite structures, due to the high ratio of strength to weight, the anisotropy of their properties is used. However, their electrical properties are usually not given much attention in the composite industry. Recycled carbon fibers have a limited length, and they are mainly used as isotropic reinforcement, limited in high concentrationsdue to decrease of the mechanical properties of plastic composites. Knowledge of their influence on dielectric properties of CFRCs expands the application potential of these materials. 


\subsection{Dielectric properties}

The action of an external electric field shifts the electrically charged particles due to the movement of the Lorenz force or the applied field. The strength of strong bonds or the thermal motion of molecules counteracts this motion [8]. If the dielectric does not contain permanent dipoles, it is a non-polar dielectric, during polarization, there is a mutual displacement of the electron shells and nuclei of the atom. If the dielectric contains molecules with a permanent dipole, the dipoles rotate in the direction of the electric field intensity due to polarization, and it is a polar dielectric. Non-polar substances usually have low values of permittivity; they have electronic and ionic polarization. Polar substances have permittivity values in a wide range; they use mainly ionic polarization [9].

Polymers are dielectrics, i.e. both the matrix and the filler used in this work are dielectrics. RCF fibers are nonpolar dielectrics, the matrix, like all polymers in general, is a polar dielectric.

\section{Dielectric constant $=$ permittivity}

Relative permittivity is a material characteristic; it is a function of internal and external parameters of the measured material. In contrast, internal factors are filler concentration, bond polarity, molecular structure, crystal lattice type, and external criteria can be considered temperature, pressure, frequency and electric field intensity [9][10].

\section{Complex permittivity and dielectric losses}

As already mentioned, the permittivity depends on the type of dielectric, on the frequency at which it is measured and on the physical conditions. Due to the alternating field, free and bound charges move in the dielectric. The energy of the electric field changes into kinetic energy, partly into heat. As this heat is not used in any way, it is considered a loss. The development of new materials aims to eliminate these losses as much as possible. Then we formulate the complex permittivity as:

$\varepsilon=\varepsilon^{\prime}-j \varepsilon^{\prime \prime}$,

Anywhere $\varepsilon^{\prime}$ is real, and $\varepsilon^{\prime \prime}$ is the imaginary part of the permittivity. The real permittivity corresponds to the relative permittivity, and the imaginary part expresses the losses. The real permittivity shows how much energy of the external electric field is stored in the dielectric. The imaginary part of the permittivity is usually much smaller than the real component. In nonpolar dielectrics, both components of permittivity are low frequencydependent due to electron polarization. In the case of polar dielectrics, these dependencies are more complicated due to the frequency, since there is an orientation dipole polarization involving the influence of the structure. At the same time, the following applies to the dissipation factor $\tan \delta$ :

$\tan \delta=\frac{\varepsilon^{\prime \prime}}{\varepsilon^{\prime}}$,

\section{EXPERIMENTAL PART}

\subsection{Materials}

An epoxy matrix system made from bisphenol A-based low-viscosity epoxy resin LR 285 was used, along with

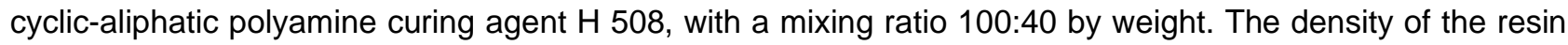
was $1,200 \mathrm{~kg} / \mathrm{m}^{3}$, and the density of the hardener was $1,030 \mathrm{~kg} / \mathrm{m}^{3}$. The specimens were filled with RCF in range of concentration from $0 \mathrm{wt} \%$ to $33 \mathrm{wt} \%$. Commercially available PAN-based Carbiso Milled Carbon Fibers (RCFs), with a density of $1,800 \mathrm{~kg} / \mathrm{m}^{3}$, were used. They have diameters of approximately $7,0 \pm 0,3 \mu \mathrm{m}$ and lengths of $100 \pm 9 \mu \mathrm{m}[5]$.

The mixture of epoxy, hardener, and fibers was stirred at room temperature for 5 min using a magnetic stirrer. Next it was poured into pre-separated circular glass molds and left to stand for $24 \mathrm{~h}$ at room temperature. 
Curing followed, the mixture was left in the oven for $15 \mathrm{~h}$ at $60^{\circ} \mathrm{C}$. The thickness of each sample varied but it was approximately $2-3.10^{-3} \mathrm{~m}$.

\subsection{Methods}

\section{SEM}

A VEGA 3 TESCAN and VEGA TS 5130 microscope were used to photograph the composite samples.

\section{Raman spectroscopy}

It was measured on a Raman DXR microscopy (Thermo Fisher). Laser $532 \mathrm{~nm}$, at each point, 20 exposures for 1 second. The Raman shift was $3600-0 \mathrm{~cm}^{-1}$. A correction for fluorescence was made. The band intensities in the Raman spectra are related to the change in the polarizability of the material.

\section{Dielectric properties}

Capacity was measured using AGILENT 4294. The measurements were carried out in the frequency range of $100 \mathrm{~Hz}-5 \mathrm{MHz}$ according to ASTM D150-12. Permittivity $\varepsilon^{\prime}$ was calculated using equation (3):

$C=\varepsilon 0 . \varepsilon^{\prime} \frac{s}{h}$,

where $\varepsilon_{0}$ is the permittivity of the vacuum $\varepsilon_{o}=8,854 \times 10^{-12} \mathrm{~F} / \mathrm{m}, h$ is the thickness of the sample and $S$ is the area of the sample.

\section{RESULTS}

\subsection{SEM}

Some information about the strength of fiber-matrix interactions and fiber surfaces can be derived from SEM images. Images of the fracture surfaces of the tested composites obtained by SEM are shown in Figure 1 (c) The figure shows the random orientation of the CFR fibers in the composite, while the detail of one fiber shows the adhesion of the interfacial interface.
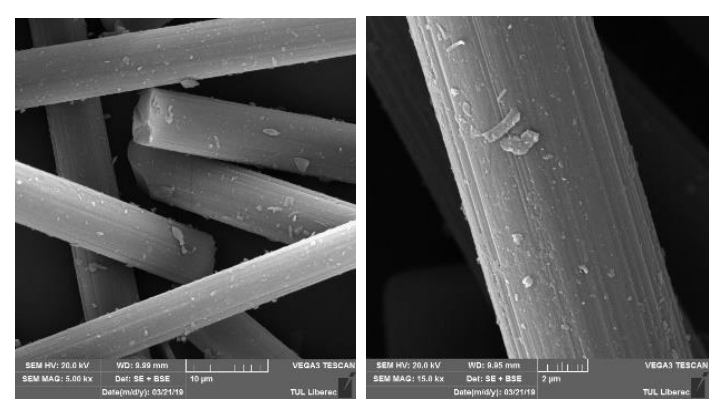

(a)

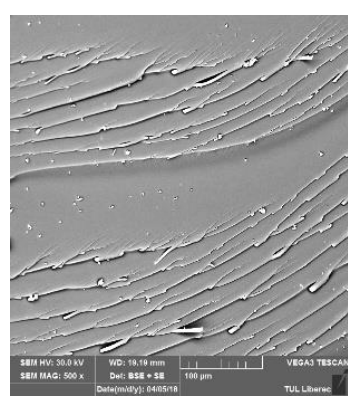

(b)

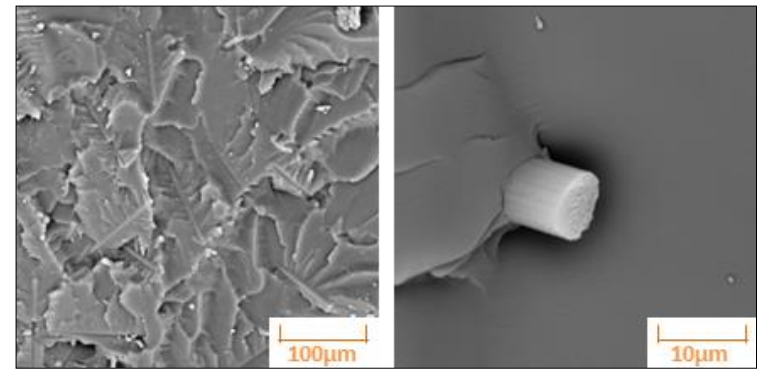

(c)

Figure 1 SEM photos: (a) RCF, (b) fracture surface of epoxy resin, (c) fracture surface of CFRCs composite 


\subsection{Raman spectroscopy}

In Figure 2 compares the Raman spectra of carbon fiber-filled epoxy composites with the spectra of the fibers themselves and the polymer matrix. In the wavelength range of $1600 \mathrm{~cm}^{-1}$, there is a significant peak (G peak) in the samples of the polymer with the fibers and the fibers themselves, i.e. there is a typical double bond $\mathrm{C}=\mathrm{C}$ for carbon fibers. The second most significant peak ( $\mathrm{D}$ peak) is in the fiber polymer samples, and the fibers themselves are in the wavelength range of $1360 \mathrm{~cm}^{-1}$. By all materials is in the wavelength range of 2900 $\mathrm{cm}^{-1}$ third considerable peak, i.e. also in the sample of the neat matrix. As we can see, this peak is the most pronounced peak for the polymer.

(a)

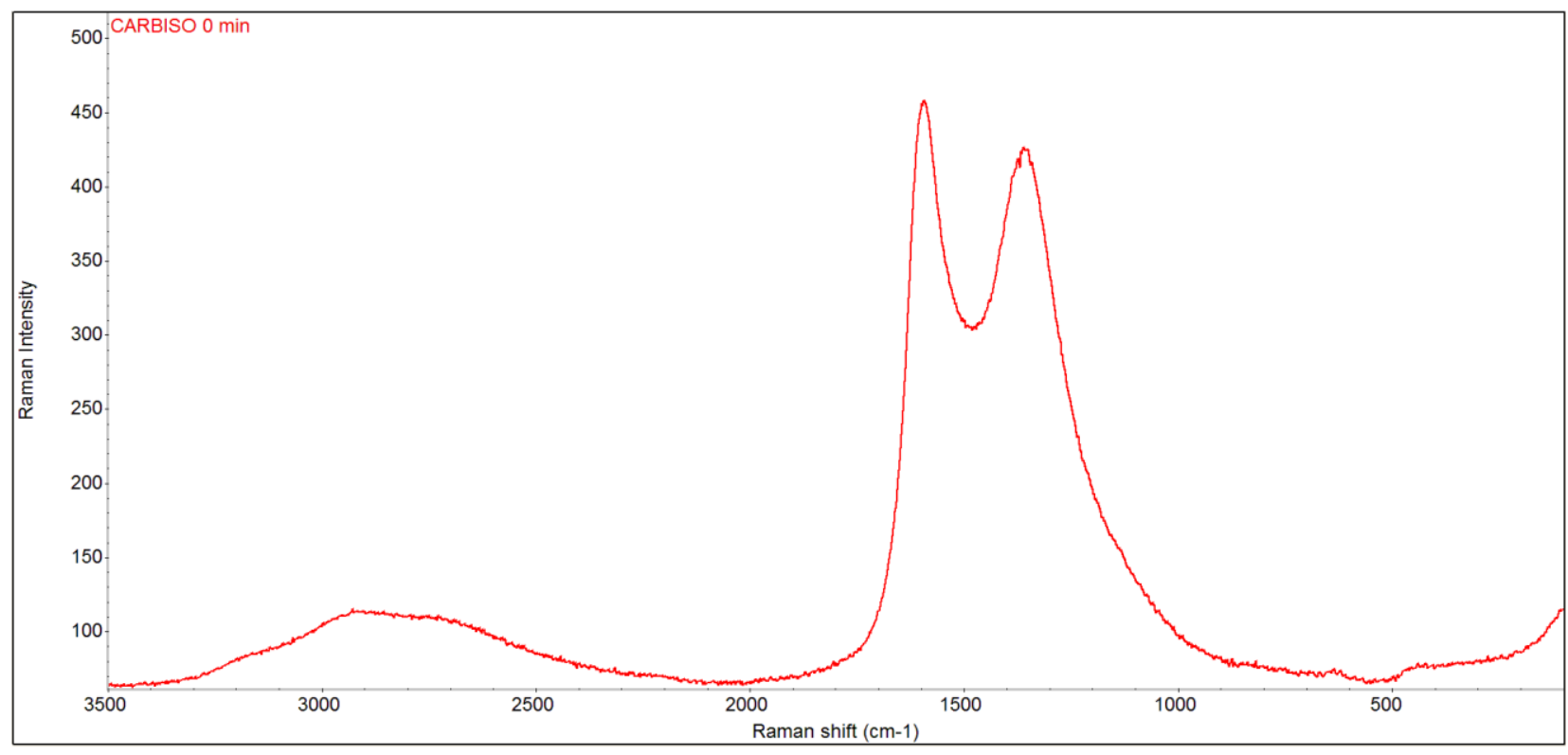

(b)

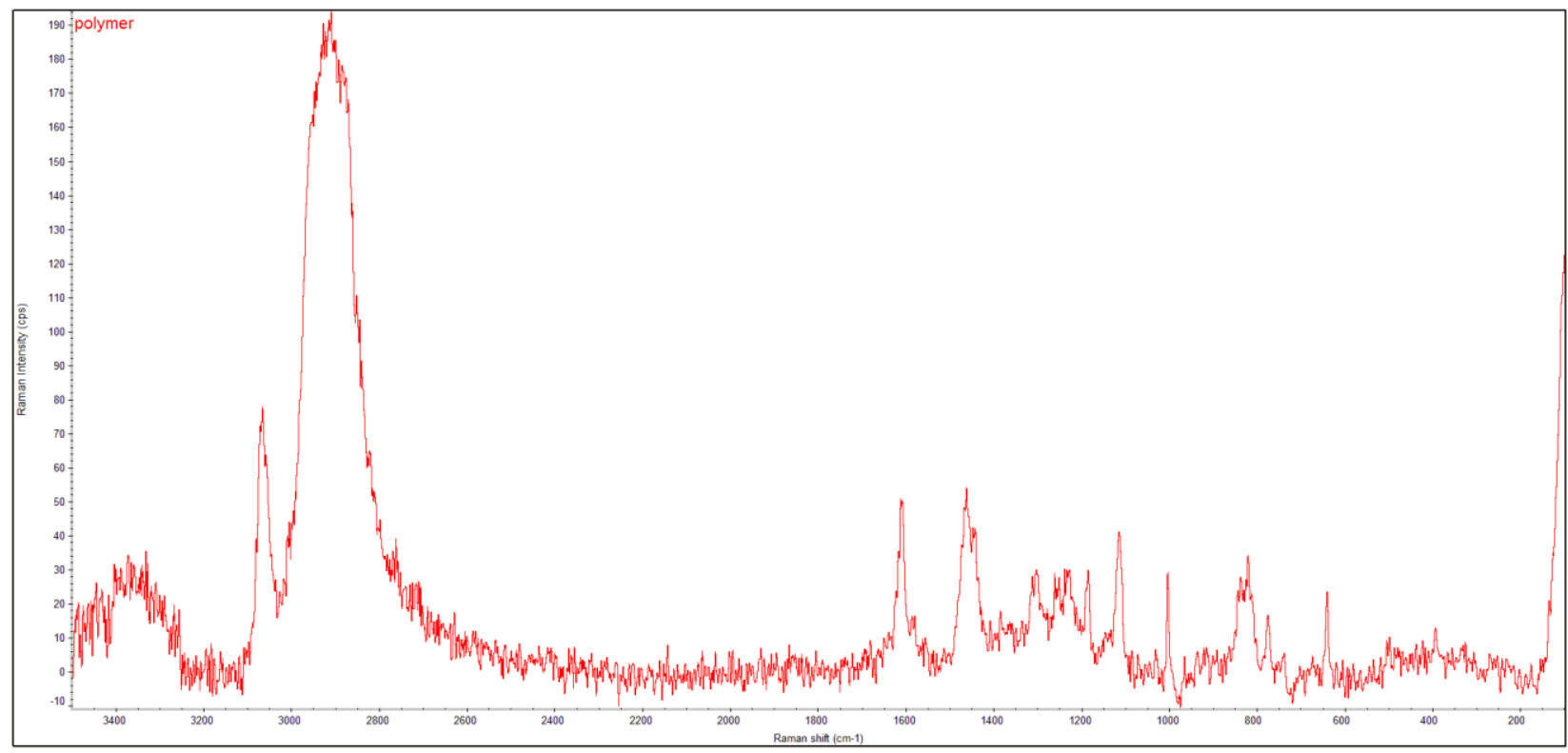

Figure 2/1 Raman spectroscopy: (a) RCF, (b) surface of epoxy resin, (c) surface of CFRCs composite 
(c)

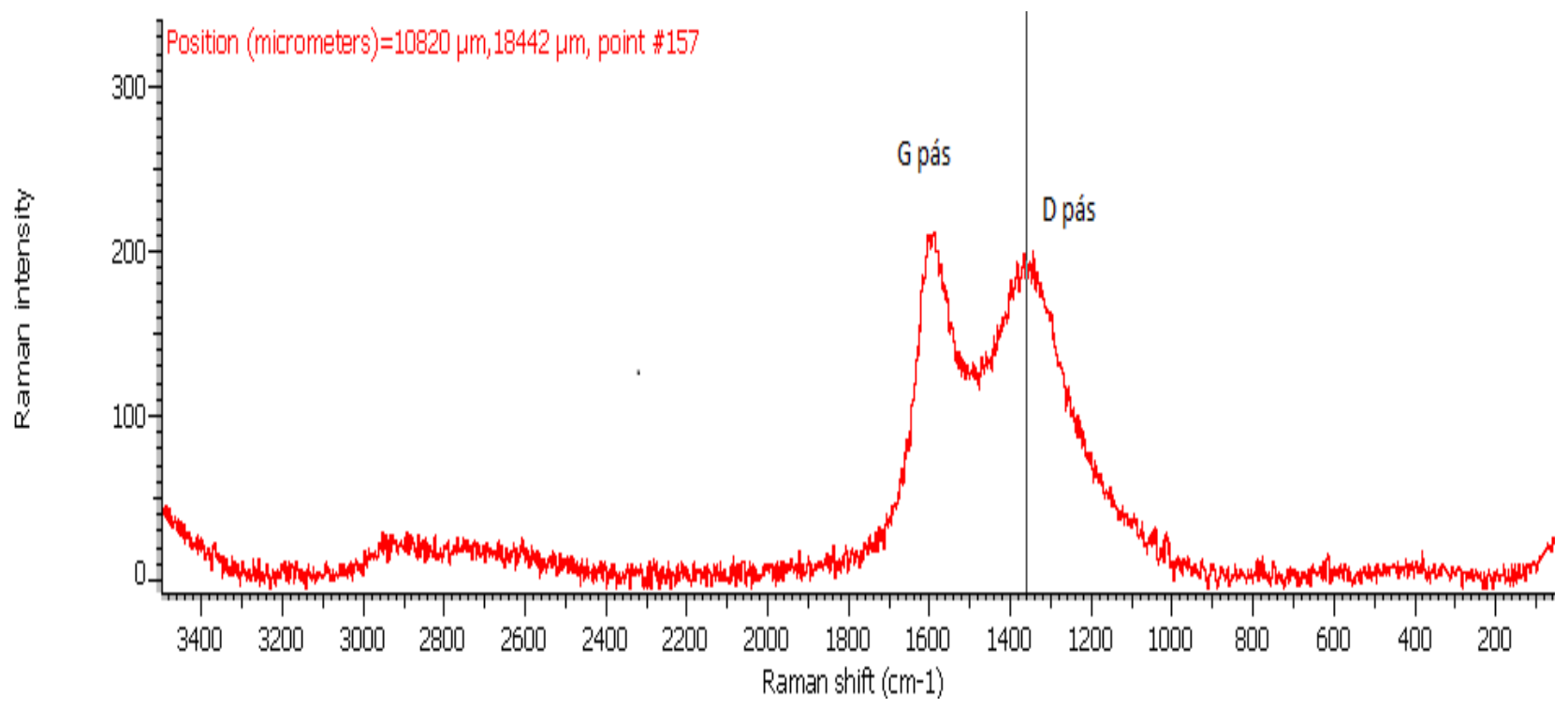

Figure 2/2 Raman spectroscopy: (a) RCF, (b) surface of epoxy resin, (c) surface of CFRCs composite

\subsection{Dielectric properties}

\section{Dielectric constant}

Figure 3 compares the real permittivity values of the whole spectrum of samples CFRCs at frequencies of $12 \mathrm{~Hz}-5 \mathrm{MHz}$. The same trend is seen; the dielectric constant decreases due to the increasing frequency. The Percolation threshold of these composites is $20 \mathrm{wt} \%$. Up to the percolation concentration, the real permittivity increases substantially linearly, above the percolation threshold at lower frequencies $(12 \mathrm{~Hz}$ and $100 \mathrm{~Hz})$ it grows exponentially.

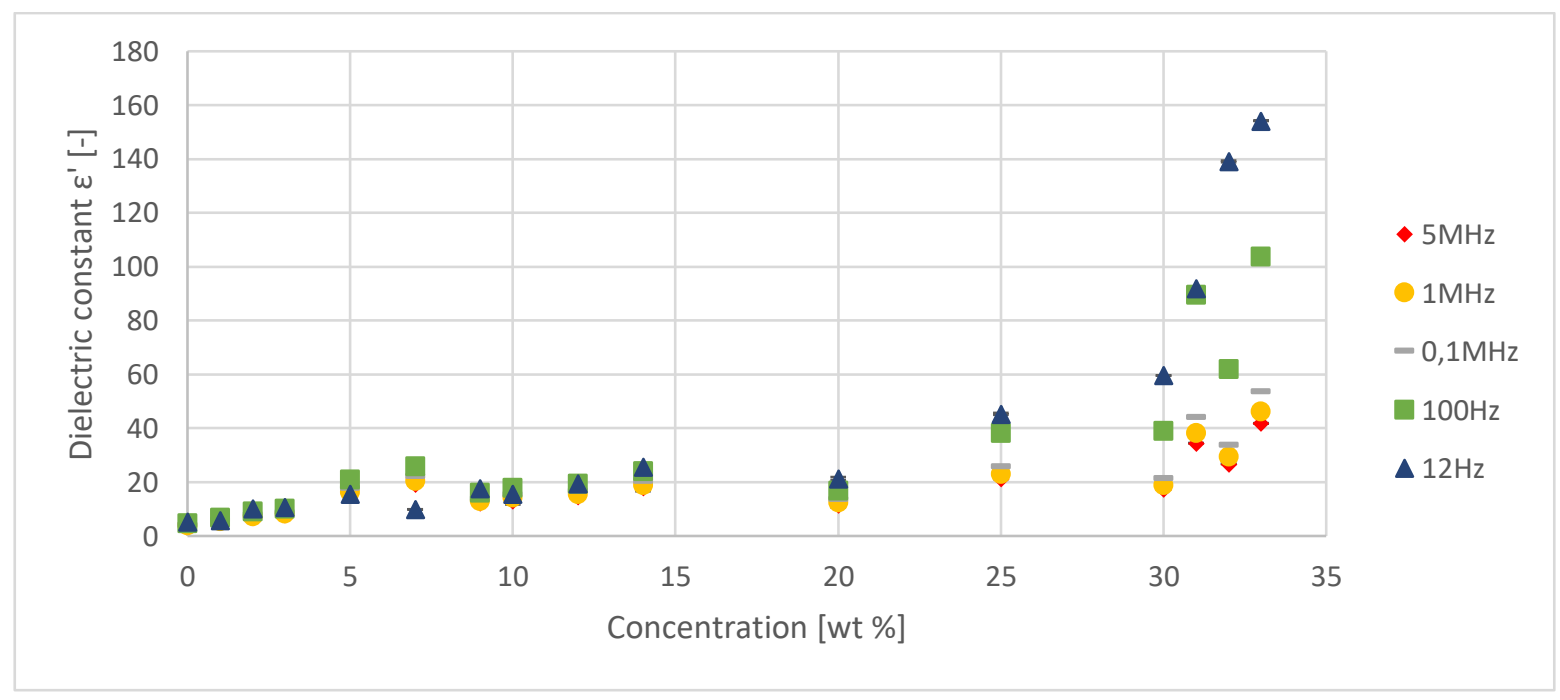

Figure 3 Variation of dielectric constant with fiber content

\section{Loss Factor}

Figure 4 compares the imaginary permittivity values of the whole spectrum of samples CFRCs at frequencies of $12 \mathrm{~Hz}-5 \mathrm{MHz}$. In general, the imaginary permittivity is higher at lower frequencies due to the interface of the 
Maxwell Wagner polarization between the epoxy resin and the RCFs. The value of $\varepsilon^{\prime}$ decreases with increasing frequency, because the dipoles orient themselves with a certain delay due to their own relaxation time.

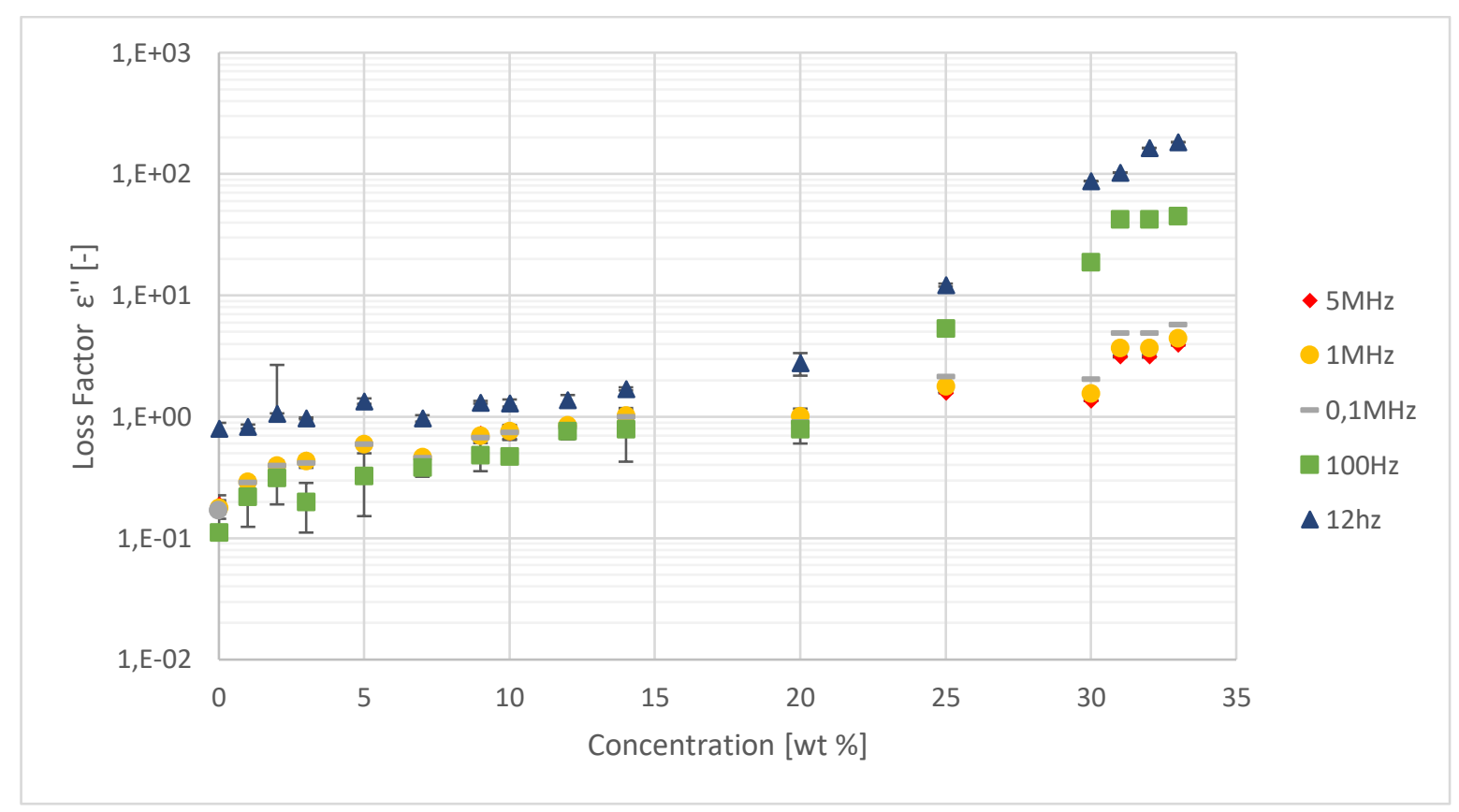

Figure 4 Variation of loss factor with fiber content

\section{Dissipation factor}

The figures show the tan $\delta$ values of the whole spectrum of samples CFRFs at frequencies of $12 \mathrm{~Hz}-5 \mathrm{MHz}$. Due to the increasing frequency, the dissipation factor decreases. In general, the magnitude of tan $\delta$, as well as other dielectric properties, is sensitive to polar sites in the polymer matrix [7]. These places increase the value of the dissipation factor. For concentrations above the percolation threshold, the tan $\delta$ decreases with increasing frequency because the induced charges do not gradually follow the reverse field, causing a decrease in electronic oscillation as the frequency increases.

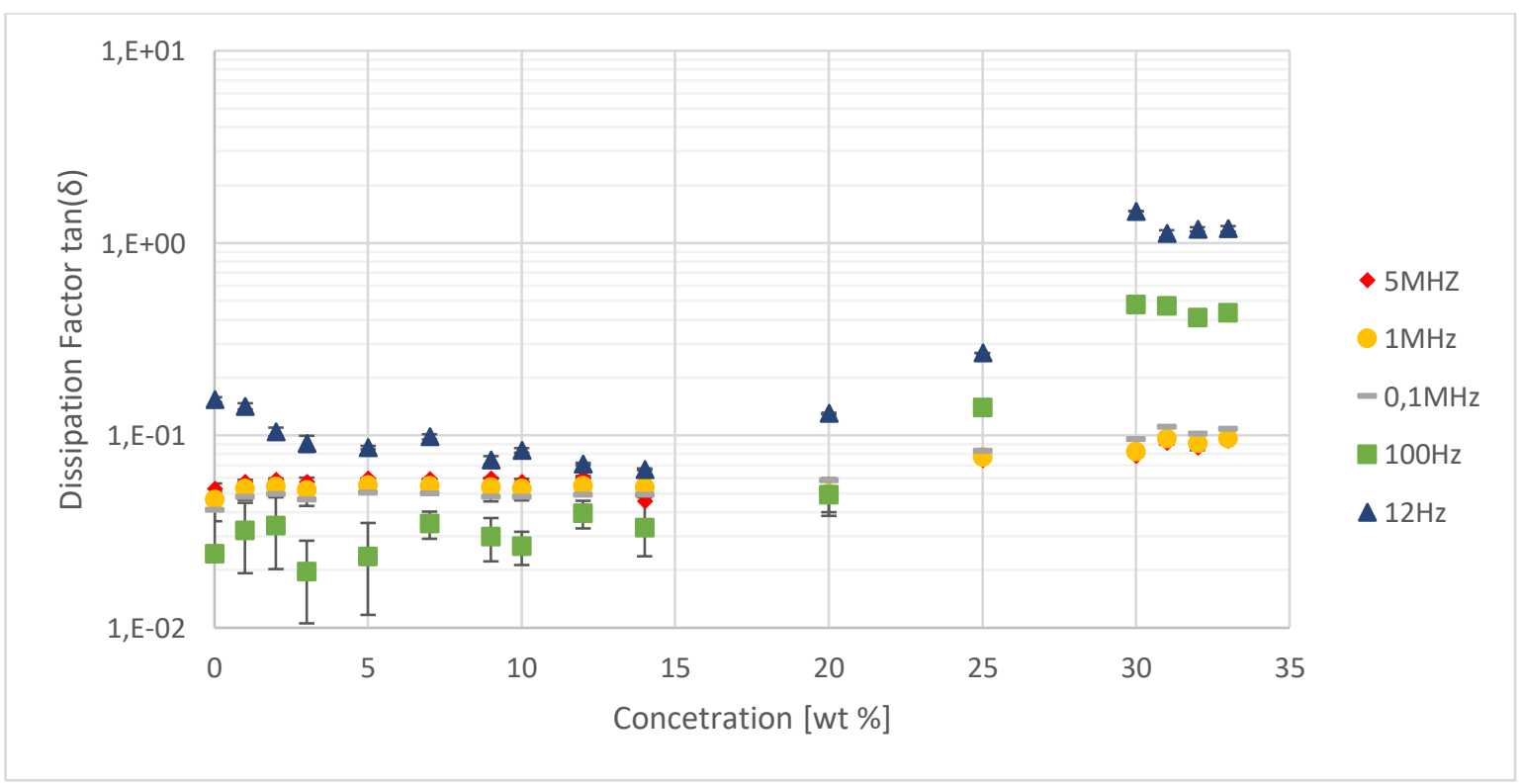

Figure 5 Variation of dissipation factor with fiber content 


\section{CONCLUSION}

The real permittivity increases due to the spatial charge created in the interface between the conductive phase and the insulating phase due to the difference in conductivity of these two phases. Charge polarization occurs when more than one material component is present or when segregation occurs in a material containing incompatible chemical sequences and when charge carriers are trapped at the interface of these heterogeneous systems [11]. The deformation of the electric field caused by the accumulation of these charges increases the total capacity of the material, which manifests itself as an increase in the dielectric constant [12].

In this experiment, it was found that the real permittivity increases with increasing concentration of particles even after reaching the percolation threshold over the entire frequency band. Usually, above the percolation threshold (i.e., when the conductivity of composites increases sharply), a sharp increase in the value of the dielectric constant is observed. Then it is not possible to measure data due to the massive increase in the conductivity of the composites. However, in the case of composites prepared from recycled RCFs, the conductivity does not reach such high values. The explanation for this behaviour may be that as the concentration of fibers increases, the distances between them decrease, and the local fields created by adjacent particles increase the permittivity values. At lower frequencies, this effect is more pronounced.

\section{ACKNOWLEDGEMENTS}

Authors are grateful for the financial support from the Student research project 2020 No. 6050 supported by Czech Ministry of Education, and by Faculty of Textile, Technical University of Liberec.

\section{REFERENCES}

[1] KŘESÁLEK, V. Electrical Conductivity of Two-Component Composites at the Percolation Threshold. Brno, 2004. Habilitation thesis. Brno University of Technology.

[2] NOVOTNÁ, J. Dielektrické vlastnosti epoxidových kompozitů plněných recyklovanými uhlíkovými vlákny. Liberec, 2021. Dissertation. Technical University in Liberec.

[3] DRZAL, L. T., RICH, M.J., LLOYD, P.F. Adhesion of Graphite Fibers to Epoxy Matrices: I. The Role of Fiber Surface Treatment. Journal of Adhesion Science and Technology. 1983, vol. 16, no. 1, pp. 1-30.

[4] MEAKINS, R. J. Progress in Dielectrics. New York: John Wiley, 1961. vol. 3, pp. 151-155.

[5] BLYTHE, T., D. BLOOR. Electrical properties of polymers. 2nd edition. Cambridge: Cambridge university press, 2005.

[6] MORGAN, P. Carbon fibers and their composites. Boca Raton, Florida: Taylor \& Francis Group, 2005.

[7] KUMAR, S., KRISHNAN, S. Recycling of carbon fiber with epoxy composites by chemical recycling for future perspective: a review. Chemical Papers. 2020, vol. 74, pp. 3785-3807.

[8] HASDENTEUFEL, J., KVĚT, K. Elektrotechnické materiály. Praha: SNTL, 1967.

[9] LIPTÁK, J., SEDLÁČEK J. Úvod do elektrotechnických materiálů. Praha: ČVUT, 2008.

[10] EDDIB A.A., CHUNG, D. D. L. Electric permittivity of carbon fiber. Carbon. 2019, vol. 143, pp. 475-480.

[11] ELIMAT, Z.M., HAMIDEEN, M.S., SCHULTE, K.I., WITTICH, H., DE LA VEGA, A., WICHMANN, M., BUSCHHORN, S. Dielectric properties of epoxy/short carbon fiber composites. Journal of Materials Science. 2010, vol. 45, pp. 5196-5203.

[12] DAHIYA, H. S., KISHORE, N., MEHRA, R.M. Effect of percolation on electrical and dielectric properties of acrylonitrile butadiene styrene/graphite composite. Journal of Applied Polymer Science. 2007, vol. 106, pp. 21012110. 